\title{
LA FORMACIÓN DE LOS \\ EDUCADORES MUSICALES EN \\ MÉXICO: RETOS Y PROPUESTAS
}

\author{
MÉXICO'S MUSIC TEACHERS: \\ Challenges And Proposals
}

Gabriel Pliego Carrasco

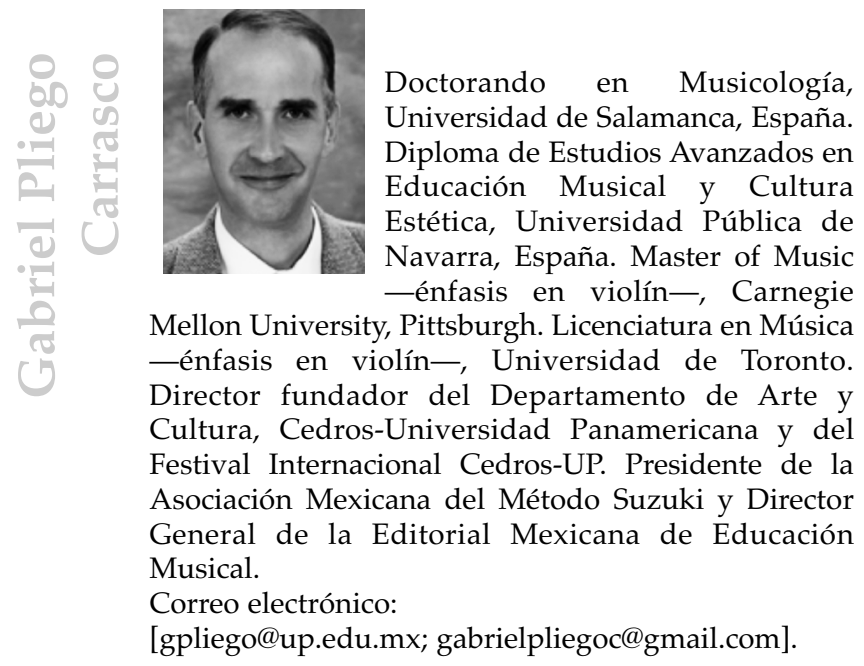

\section{RESUMEN}

En México, las reformas curriculares vigentes para la educación musical en los niveles básicos obligatorios, presentan dilemas que desfavorecen la consecución de los propósitos planteados por ellas mismas. Las principales razones son tres: los programas de educación musical no están realizados sobre un sistema de pensamiento o análisis profundo de la naturaleza de la música y su educación; en estas reformas no se precisa el perfil deseado para el educador musical, y existe una limitada cantidad de opciones para la formación profesional del educador musical. 
Es necesaria una reflexión informada y profunda acerca de la viabilidad de los programas actuales de educación musical, y una gama de opciones serias de formación universitaria del profesorado de educación musical, en ámbitos de creación musical y prácticas didácticas reales.

El objetivo de esta investigación es considerar a la filosofía praxial de la educación musical, junto con el análisis del programa universitario de educación musical de la Escuela Nacional de Música (ENM) de la Universidad Nacional Autónoma de México (UNAM), como fundamento que ofrece bases y lineamientos para el desarrollo de un currículo universitario de educación musical en la Ciudad de México. Estos fundamentos definen el perfil de un educador musical y brindan, a su vez, los pilares para el desarrollo de los programas de música para la educación básica en México.

Palabras clave: educación musical; currículo; formación del profesorado; competencias musicales; prácticas docentes; filosofía praxial.

\section{ABSTRACT}

The latest music education curriculum reforms regarding basic compulsory levels in Mexico, suffer from irreconcilable differences with the educational opportunities available. There are two major causes for this problem: the attempt to cover far too much content and the fact that the profile for the educator is not well defined.

Parallel to these problems, the lack of options for the training of music educators makes it impossible to carry out any educational plan that has significant social impact through music.

We need to reflect deeply and intelligently on the viability of the current music education programs, and the need to offer more options for university programs for music education teachers in contexts of active involvement in music making and teaching practices.

Key words: music education; curriculum; teacher training; musicianship; student teaching; praxial philosophy. 


\section{INTRODUCCIÓN}

La presente investigación se fundamenta en los resultados de un estudio cualitativo del programa universitario de educación musical de la Escuela Nacional de Música (ENM) de la UNAM ', realizado bajo la perspectiva del análisis crítico de la filosofía praxial de la educación musical. Es importante señalar que, en la Ciudad de México, donde existen 3,354 escuelas primarias y 1,405 escuelas secundarias - entre instituciones privadas y públicas para ambos $\operatorname{casos}^{2}$-, el programa de educación musical de la $\mathrm{ENM}^{3}$ es la única opción universitaria. Además, este programa enfrenta el reto de contar con un promedio de 5.3 egresados por año, entre 2004 y $2010^{4}$.

La realización de este trabajo se ha llevado a cabo conforme a la metodología de un diseño de estudio de caso múltiple; la recolección de los datos se efectuó por medio de la observación, recolección de documentos y las entrevistas abiertas y semiestructuradas a 15 alumnos, 7 egresados y 7 profesores de educación musical de la ENM de la UNAM, además de 6 profesores de los programas de instrumentistas o composición de la misma ${ }^{5}$. Las entrevistas se llevaron a cabo entre

1 La investigación completa, de la cual se desprende el presente trabajo, implica el análisis comparativo entre los programas universitarios de educación musical de la Universidad Nacional Autónoma de México, la New York University y la Universidad de Salamanca, España. Para los fines del presente trabajo solo se juzga necesaria la información referente al programa de la Universidad Nacional Autónoma de México.

2 Secretaría de Educación Pública, «Principales cifras», en [http:/ / www.dgpp.sep.gob.mx/ principalescifras/], consulta: 22-VI-2011.

3 El Conservatorio Nacional de Música del Instituto Nacional de Bellas Artes (INBA) ofrece la Licenciatura en Enseñanza Musical Escolar. Estos estudios del Conservatorio no se consideran en el presente estudio, debido a que no pertenecen a una institución universitaria y, por lo tanto, no goza de todas las implicaciones que esto significa.

4 Datos proporcionados por la Secretaría de Servicios y Atención Estudiantil de la ENM-UNAM, consultada el día 30 de junio de 2011.

5 La investigación comprendió, adicionalmente, las siguientes entrevistas en la New York University: 7 alumnos, 3 egresados y 6 profesores de educación musical, 5 profesores de los programas de instrumentistas o composición; y en la Universidad de Salamanca: 10 alumnos, 5 egresados y 6 profesores de educación musical, 5 profesores de los programas de instrumentistas o composición; y en la Universidad de Salamanca: 10 alumnos, 5 egresados y 6 profesores de educación musical, 5 profesores de los programas de instrumentistas o composición. 
el 23 de febrero y el 29 de mayo de 2009. El primer análisis de ellas se realizó con la ayuda del programa computacional HyperRESEARCH Qualitative Analysis Tool, versión 2.8.

En el primer análisis de las entrevistas, y después de eliminar la información irrelevante, se eligieron unidades de significado organizadas - de acuerdo a las similitudes de contenidos y temática- en 372 categorías, las cuales se reagruparon y compactaron creando 28 núcleos temáticos distribuidos, a su vez, en cuatro ejes temáticos.

El criterio para la elección de los ejes temáticos fue, según la filosofía praxial de la educación musical, que la naturaleza de la música comprende una

[...] tétrada de dimensiones complementarias que involucran (1) un realizador, (2) un tipo de realización, (3) algo realizado, y (4) el contexto completo donde los realizadores realizan lo que realizan ${ }^{6}$.

Esto es, un creador o intérprete, un medio por el cual se crea o interpreta música: interpretación, improvisación, composición, arreglo o dirección, el producto audible u obra musical, y el entorno donde todo lo demás toma vida.

Como contexto general, se expone a continuación una aproximación a la legislación actual de la educación musical en México.

\section{LA EDUCACIÓN MUSICAL EN LOS PROGRAMAS VIGENTES PARA LA EDUCACIÓN DE CARÁCTER OBLIGATORIO}

La Reforma Integral de la Educación Básica (RIEB) ${ }^{7}$, centra su atención en la oferta de un modelo educativo basado en competencias: la

6 Elliott, Music Matters, p. 40.

7 En los años 2004, 2006 y 2009 se llevaron a cabo las reformas de educación preescolar, educación secundaria y educación primaria, respectivamente, las cuales comprenden la normativa oficial actual de la educación básica obligatoria en México. Estas tres reformas conforman la Reforma Integral de la Educación Básica (RIEB) que se caracteriza, principalmente, por la articulación entre los tres niveles educativos y el desarrollo de competencias. 
educación básica (preescolar, primaria y secundaria) se presenta, así, articulada a través de planes y programas. La profesionalización y capacitación de todo el profesorado se señala como una prioridad para alcanzar las metas propuestas.

A lo largo de todos los documentos que dan cauce a esta Reforma, las referencias a la educación artística presentan una valoración alta como medio para alcanzar los objetivos que se plantean:

Es necesario romper con la inercia tradicional de la educación artística como una asignatura «recreativa» o de «relleno»; otorgarle el valor necesario y el sentido formativo creará, en el alumno, mayores posibilidades y expectativas de expresión que trascenderían en su desarrollo ${ }^{8}$.

Se mencionan, a continuación, solo tres propósitos de esta asignatura:

Estimular las habilidades cognitivas, a través de la formación artística para resolver, en forma creativa, situaciones de su vida cotidiana. Fortalecer la construcción de la identidad personal para que el alumno sea capaz de reconocer y valorar a sus competencias. Utilizar sus expresiones lúdicas de exploración y experimentación artística con el objeto de comprender, y en su momento transformar, su entorno ${ }^{9}$.

A pesar de la importancia que se le asigna a la educación artística en la RIEB, se encuentran las siguientes incongruencias entre los objetivos que propone la Reforma: la cantidad de horas asignadas, y la inclusión de cuatro diferentes disciplinas artísticas - música, teatro, expresión corporal y danza-y artes visuales, dentro de una misma asignatura.

En preescolar se señala que:

De acuerdo con el enfoque de este programa, centrado en competencias, se asume que no hay una distribución predeterminada del tiempo para el

8 SEP, Plan de Estudios, Etapa de Prueba, p. 253.

$9 \quad$ Ibidem, p. 251. 
trabajo pedagógico en la jornada diaria; su distribución es decisión de la educadora; ella es quien, con base en el conocimiento de sus alumnos y de las circunstancias particulares en que realiza su labor docente, puede encontrar las mejores formas para aprovechar el tiempo de la jornada escolar ${ }^{10}$.

En preescolar, la expresión y apreciación artísticas —uno de los seis campos formativos y de competencias que se buscan desarrollar en los alumnos-, se divide en los siguientes aspectos: expresión y apreciación musical; expresión y apreciación plástica; expresión corporal y apreciación de la danza; expresión dramática y apreciación teatral. Debido al sentido abierto de la propuesta curricular para preescolar, la educadora tiene la libertad de enseñar estos cuatro aspectos diferenciadamente, asignándoles el tiempo que ella valore necesario para alcanzar los objetivos propuestos.

Con este antecedente, la educación musical, si así lo desea la educadora en cuestión, puede jugar un papel significativo en los alumnos durante su educación preescolar; el reto es que ella tenga la capacitación adecuada para impartir esta área de la formación infantil. Sin embargo, por esta situación de apertura curricular, al mismo tiempo existe el riesgo de que, en preescolar, la educación musical quede relegada a un estado de marginación respecto a los otros aspectos del campo formativo artístico.

Para la educación primaria, la situación es más desafortunada aún, puesto que la asignatura de Educación Artística comprende, dentro de la misma materia, las disciplinas artísticas de: música, teatro, expresión corporal y danza, y artes visuales. Para la consecución de los objetivos se cuenta con una hora semanal, lo que hace un total de 40 horas en el año. Esto implica que, en promedio, para la educación musical únicamente se ofrecen 10 horas lectivas al año, que comúnmente son de 40 o 50 minutos; esto sin tomar en cuenta que, generalmente, se espera que los profesores y alumnos, dentro de esas mismas horas,

10 SEP, Programa de Educación Preescolar 2004, p. 126. 
preparen presentaciones para festividades especiales en la escuela (tales como Navidad, día de las madres, concursos del Himno Nacional y otras).

Si tomamos el quinto grado de primaria, como ejemplo, de acuerdo al libro oficial de texto gratuito de la asignatura de Educación Artística, en este grado se esperan cubrir en la disciplina de música los siguientes temas: comprensión de los compases de 2/4,3/4 y 4/4; lectura de valores de negra y corchea, con sus respectivos silencios, e integrándolos a cualquiera de los compases mencionados. Con los conocimientos anteriores, la expectativa es que un alumno sea capaz de interpretar una partitura rítmica con un instrumento de percusión. Todo esto, como ya se señaló, debe ser cubierto en menos de 10 horas.

Al reto del poco tiempo asignado a la Educación Artística en primaria, se le añade el dilema de que es un solo profesor quien debe impartir los contenidos de las disciplinas artísticas de música, teatro, expresión corporal y danza, y artes visuales... Por razones de logística y presupuesto, no es de esperarse que, para una sola asignatura, se cuente con cuatro maestros con especialidades distintas; por lo tanto, se necesita que ese profesor posea las competencias necesarias para impartir esas cuatro disciplinas artísticas. Que una escuela pública, en este país, cuente con un profesor especialista en una de esas cuatro disciplinas artísticas es, en sí, ya un gran reto económico y vocacional, pero que domine las cuatro disciplinas, se presenta como una cuestión irrealizable.

La propuesta del Plan de Estudios 2006 (RES 2006) para secundaria, sufre de retos todavía más perjudiciales. Este plan propone que la asignatura de Artes se considere como obligatoria, con el estudio de una de las siguientes cuatro opciones de expresiones artísticas: danza, música, teatro o artes visuales; hasta aquí, igual que para la primaria, pero la elección de la rama artística que se imparte queda a la libre elección del director o coordinadores de la secundaria en cuestión. Esto implica que en muchas secundarias los alumnos, si así lo deciden los directivos, no tengan acceso a 
ningún tipo de estudio musical. Lo anterior es contrario a lo que en los mismos documentos curriculares se señala cuando se afirma que:

En la escuela es fundamental propiciar que todos los alumnos hagan música, pues los seres humanos sin excepción tienen la capacidad y el derecho para ello ${ }^{11}$.

A toda la anterior problemática se agrega que no se especifican, en ningún documento de las reformas educativas actuales, los requerimientos mínimos para impartir las materias de Educación Artística.

En la misma concepción de la naturaleza de las asignaturas de Educación Artística, se encuentran inconsistencias básicas respecto al arte en general y a la educación musical en particular, por las razones que se exponen a continuación.

En los documentos de la RIEB, al hacer referencia al estudio de la música, se encuentran afirmaciones como la siguiente:

La música es un lenguaje que puede escribirse y leerse porque tiene signos, figuras y símbolos que representan sonidos o formas de reproducirlos en un instrumento musical o con la voz ${ }^{12}$.

Esta postura descartaría muchas y muy bellas prácticas musicales del mundo. Este hecho es palpable en los lugares donde la música no es representada con ningún tipo de notación gráfica, como lo muestra la música de África, la India y la música tradicional de China. De hecho, una de las pocas excepciones en las cuales sí existe una notación gráfica es la música tradicional de concierto de Europa Occidental, surgida a mediados de la Edad Media. Además de los ejemplos ya mencionados, se encuentran: la improvisación jazzística, el gameland balinés, la misma música folklórica mexicana que ha llegado hasta nosotros gracias a la tradición oral y que solo en tiempos

11 SEP, Artes, música, p. 21.

12 SEP, Educación artística. Quinto grado, p. 20. 
actuales ha sido transcrita a la notación musical europea; y no digamos la música de las grandes culturas prehispánicas que, de manera importante, ha permeado las tradiciones de muchas culturas y pueblos contemporáneos. Por su naturaleza, pues, la música se muestra como un hecho multicultural en sí mismo.

Otro problema sobre la concepción que la reforma educativa en México tiene respecto a la naturaleza de la asignatura de Educación Artística, es el referido a asumir que la música, las artes visuales, la danza y el teatro comparten «muchas cosas en común», y por tanto pueden ser enseñadas en una misma asignatura:

[...] cada arte interpretativo y no interpretativo es una clase específica de práctica humana que descansa sobre una forma independiente de pensamiento y conocimiento situado. Por lo tanto, cada clase de conocimiento artístico necesita ser enseñado y aprendido en su propio contexto a través de involucrarse activamente en la creación artística ${ }^{13}$.

Esto no quiere decir que buscar las transversalidad y multidisciplinariedad de las asignaturas no sea deseable; al contrario, esta recomendación es loable y se toma en consideración en la RIEB. De hecho, existen diversas manifestaciones artísticas valiosas que comparten, en un mismo espacio, dos o más expresiones artísticas (como sería el caso de la ópera europea, donde entran en juego la música, la danza, el teatro y las artes visuales). Pero, ¿qué tantos procedimientos, reglas y contenidos comparten estas cuatro áreas artísticas que - se asumepueden ser enseñadas en una misma clase?, ¿qué perfil se requeriría para que un mismo profesor ofreciera a sus alumnos experiencias reales, contextuadas y significativas, en los ámbitos de la música, las artes visuales, la danza y el teatro dentro de una misma asignatura? Más aún: ¿todo lo anterior podría enseñarse en solo 40 o 50 minutos semanales, con más de 25 niños al mismo tiempo, en el caso de la primaria? La reflexión anterior coloca a la educación musical, dentro de la RIEB en México, en un estatus de utopía educativa. 


\section{LA FILOSOFÍA PRAXIAL DE LA EDUCACIÓN MUSICAL}

En cualquier ámbito de la educación, el diseño de un programa de formación del profesorado debe realizarse, primeramente, tomando en cuenta la naturaleza del contenido de la materia en cuestión; en este caso, la naturaleza de la música. Esto se debe a que el educador:

[..] no solo necesita entender que algo es así; el maestro además debe entender por qué es así, sobre qué bases su justificación puede ser afirmada, y bajo qué circunstancias nuestras creencias en esas justificaciones pueden ser debilitadas e inclusive negadas ${ }^{14}$.

Además, el diseño de cualquier programa educativo requiere elaborarse con base en unos principios de pensamiento que fundamenten la crítica y la propuesta.

Para este trabajo se ha elegido, como base de pensamiento para el desarrollo curricular del profesorado de educación musical, a la filosofía praxial de la educación musical, corriente de pensamiento propuesta por el doctor David Elliott, profesor de la New York University.

Son dos las premisas en las que descansa esta filosofía de la educación musical:

La primera es que la naturaleza de la educación musical depende de la naturaleza de la música. La segunda es que el significado de la educación musical depende del significado de la música en la vida de los humanos ${ }^{15}$.

Se desprende de estas premisas que, en primer lugar, deben clarificarse los conceptos y fundamentos de lo que llamamos «música».

Las definiciones tradicionales que pretenden explicar el hecho musical carecen, en su gran mayoría, de conceptos incluyentes para la inmensa variedad de expresiones musicales que existen en el mundo. Explicar qué es la música por medio de sus componentes melódicos,

14 Schulman, The Widsdom of Practice, p. 202.

15 Ibid., p. 8. 
armónicos, rítmicos y demás elementos estructurales $-\mathrm{o}$ lo que es lo mismo: a través de sus cualidades estéticas-, excluye inmediatamente muchas prácticas musicales. ¿Qué tienen en común estructuralmente una sinfonía de Brahms y una obra para jembes de Costa de Marfil? Esta última carece, por lo menos en el entendimiento musical occidental, de armonía y melodía; ¿y los ritmos de esta música de Costa de Marfil en qué se relacionan con los de una obra de John Cage? ${ }^{16}$. Parecería que los ejemplos mencionados pertenecen a ámbitos muy distantes de la creación humana. Pero es precisamente este concepto, el de «creación humana», el que nos da luces sobre el problema planteado:

[...] lo que es la música, en su raíz, es una actividad humana [...]. Fundamentalmente, la música es algo que la gente hace ${ }^{17}$.

La música es, antes que nada: creación humana. Esta aparente obviedad, cuando se le considera en profundidad, ofrece posibilidades novedosas para el desarrollo de un concepto más enfocado de lo que se entiende por «música».

La noción de que la música es, en esencia, creación humana, inmediatamente pone en contexto y explica el hecho musical, y el papel que juegan las personas en la creación musical: se requiere de una persona que interprete, improvise, componga, arregle o dirija un «algo» llamado música; en un lugar y tiempo específicos; de acuerdo a unas tradiciones y normas que lo rodean; y pensando en unos auditores que esperan ciertas características de esa música producida. Esta cadena de argumentos establece las bases de lo que se conoce como «filosofía praxial» de la educación musical.

La primera persona en utilizar el término «praxial» en el campo de la filosofía de la educación musical fue el doctor Philip Alperson ${ }^{18}$,

${ }^{16}$ John Cage (1912-1992) es considerado uno de los compositores estadounidenses más influyentes del siglo XX y pionero de la música aleatoria. $N$. del e.

17 Elliott, Music Matters, p. 39.

18 Alperson, "What Should One Expect", p. 233 y ss. 
profesor de filosofía de la música, el arte y la cultura en la Temple University, en Filadelfia.

El profesor Alperson utilizó el término praxial, derivado de la palabra «praxis», basándose en la idea aristotélica de entenderla como el razonamiento o pensamiento crítico para obtener resultados correctos, realizados bajo unas normas y estándares en una situación o dominio específico en beneficio de las personas. Por lo tanto, no solo se está hablando de acciones en abstracto, sino de acciones relacionadas a unos seres humanos concretos en lugares y contextos determinados.

Esta postura se opone a la tradicional idea de la experiencia estética, la cual implica:

Un tipo especial de evento emocional o placer desinteresado que supuestamente surge exclusivamente de la concentración del escucha en las cualidades estéticas de una obra musical, más allá de cualquier conexión moral, social, religiosa, política, personal, o de otra práctica conexión que estas cualidades puedan encarnar, apuntar o representar ${ }^{19}$.

En términos musicales, la experiencia estética significa que la música es una colección de objetos u obras «mesurables»; que las obras musicales existen exclusivamente para ser escuchadas estéticamente, pues solo interesan sus elementos estructurales o cualidades estéticas ${ }^{20}$ : melodía, armonía, ritmo, dinámica, etcétera; que el valor de la obra musical es siempre intrínseco o interno; y que si se escucha una obra «estéticamente», el auditor apreciará, necesariamente, una experiencia estética.

Este pensamiento estético tiene como repercusión pedagógica desvalorar la importancia de las prácticas musicales locales y tradicionales en favor de enfocarse, por sus complejas estructuras internas, en las obras musicales de corte principalmente europeo barroco, clásico o romántico. Al mismo tiempo, por enfocarse en las estructuras internas

19 Elliott, Music Matters, p. 23.

20 Contrarias a las cualidades artísticas, donde las cualidades de una obra son entendidas como atributos, reflejo de tradiciones y prácticas donde se realiza la obra. 
de la música, la idea de la experiencia estética también posee como consecuencia que muchos programas de educación musical menosprecien la importancia de la interpretación o creación musical en favor de los aprendizajes verbales: conocer datos, entender la teoría o saber de historia y, en el mejor de los casos, limitarse a la audición de la llamada música de concierto, sin considerar a todas las demás opciones musicales del mundo. Es por esto que muchos defensores de la educación musical, entendida como educación estética, comprenden a la interpretación o creación musical solo como un medio hacia el aprendizaje musical y no como un fin; para ellos es más importante «entender» la música —entender en el sentido de saber «cosas» acerca de la música-que crearla o interpretarla.

La filosofía praxial de la educación musical, tomando en cuenta la naturaleza intrínseca de la música, propone todo lo contrario: considera que el conocimiento musical es esencialmente un conocimiento procesual ${ }^{21}$. Este concepto, desarrollado por Donald Schön se refiere a la idea de que:

A menudo no podemos decir qué es lo que sabemos. Cuando tratamos de describirlo no sabemos qué decir, o hacemos descripciones que son obviamente inapropiadas. Nuestro conocimiento es de ordinario tácito, está implícito en nuestros patrones de acción y en nuestra sensación respecto a las cosas con las que estamos tratando. Parece correcto decir que nuestro conocimiento se da desde la acción ${ }^{22}$.

Comprender la naturaleza procesual de las competencias musicales apunta hacia unas importantes consecuencias pedagógicas a tomar en cuenta:

[...] mientras el desarrollo del pensamiento verbal depende mucho de los conceptos verbales, el pensar desde la acción práctica depende mucho de conceptos no verbales o prácticos ${ }^{23}$.

${ }^{21}$ Además del conocimiento procesual, Elliott considera que el conocimiento musical incluye, aunque en menor medida, los siguientes conocimientos: el formal o verbal, el informal, el intuitivo y el meta-cognitivo.

22 Schön, El profesional reflexivo, p. 55.

${ }^{23}$ Ibid., p. 58. 
Desde esta perspectiva, en los diseños de programas curriculares de educación musical se debe dar preponderancia a la inclusión de la educación a través de la creación musical en cualquiera de sus manifestaciones: interpretación, improvisación, composición, arreglo o dirección y, evidentemente, a la audición que va forzosamente unida a estas expresiones musicales.

Esto implica que, de acuerdo a la filosofía praxial de la educación musical, el objetivo de la educación musical es desarrollar musicianship ${ }^{24}$, palabra que en la presente investigación se traduce como «competencias musicales», debido a que se entiende por esta palabra lo que Corominas señala como competencias:

Tienen relación con la acción: [la competencia] se desarrolla, se actualiza, en la acción; está vinculada a un contexto, a una situación dada; integra diferentes elementos: saberes, procedimientos, actitudes, normas; facilita la resolución eficaz de situaciones laborales conocidas o inéditas; y es educable ${ }^{25}$.

La implicación más importante a tomar en cuenta, respecto a las características procesuales del quehacer musical en cualquiera de sus facetas, es que los educadores musicales deliberadamente busquen situaciones de enseñanza-aprendizaje en las que los alumnos desarrollen competencias musicales en situaciones lo más reales posibles, de acuerdo a las normas y tradiciones de la práctica musical que se pretende estudiar. Por lo tanto,

[...] la creación musical auténtica (la cual siempre incluye la audición inteligente de la música que uno está creando) debe ser el enfoque de todo currículo de educación musical ${ }^{26}$.

${ }^{24}$ Frecuentemente se encuentran como traducción al español de la palabra inglesa musicianship las siguientes acepciones: musicalidad, habilidad musical o maestría musical. Sin embargo, ninguna de estas opciones comprende todo lo que la palabra abarca en los textos de David Elliott.

25 Corominas, Percepciones del profesorado, p. 301.

26 Elliott, Music Matters, p. 74. 
Con base en esto, se presenta un esbozo de los fundamentos para desarrollar un currículo para la formación universitaria del profesorado de educación musical.

\section{SITUACIONES REALES DE CREACIÓN Y ENSEÑANZA MUSICAL, COMO FUNDAMENTO DEL CURRÍCULO FORMATIVO DEL PROFESORADO}

El marco teórico de esta investigación, basado principalmente en las nociones propuestas por la filosofía praxial de la educación musical, sugiere que el objetivo primario de la educación musical es el desarrollo de competencias musicales; para que los educandos sean partícipes de los valores que ofrece la educación musical -en la escuela o en la formación universitaria-, es necesario que las competencias musicales sean desarrolladas a través de, por lo menos, una práctica real musical (interpretación, improvisación, composición, arreglo o dirección), ordenando el conocimiento verbal o teórico a un plano exclusivamente de apoyo para el desarrollo de las prácticas musicales en estudio ${ }^{27}$.

Por lo tanto, es requerimiento indispensable que la formación universitaria del profesorado de educación musical se dirija primordialmente al desarrollo de las competencias musicales en los futuros profesores de educación musical, puesto que las competencias musicales serán su objeto de enseñanza-aprendizaje. Aunado al desarrollo de estas competencias, es imprescindible buscar un «equilibrio entre la competencia en la disciplina enseñada y la competencia pedagógica» ${ }^{28}$. Esto es, que los alumnos universitarios aprendan adecuadamente lo que deberán enseñar y aprendan cómo enseñarlo, pero siempre en situaciones reales de creación musical y de enseñanza-aprendizaje.

27 Esta postura no desestima el estudio de la teoría de la música y la musicología histórica y comparada; al contrario, lo que está proponiendo es situarlas en su lugar más conveniente respecto a la educación musical.

28 Delors, La educación encierra un tesoro, p. 166. 
Los hallazgos de esta investigación muestran, como se atestigua en los fragmentos seleccionados de las entrevistas realizadas [se transcribe el tono coloquial con el que se respondía], que en la Escuela Nacional de Música no existe una propuesta clara de desarrollo de competencias musicales a través de la creación musical ${ }^{29}$ :

Hay maestros [de instrumento] que de plano dicen "ay, Educación Musical... No entras a mi clase" (Alumno no. 3).

Lo que tienen los demás que no tienen ellos [los alumnos de Educación Musical] es, otra vez, la práctica musical efectiva y constante, o sea, que efectivamente $[\ldots]$ se les exija tocar de todo, pues, que se les exija un nivel musical al mismo nivel que a todos los demás, un nivel de compromiso igual que todos los demás (Profesor de Educación Musical no. 2).

Entonces, qué es lo que vas a enseñar, o sea, tu materia, tu objeto de estudio está... de lado, y te estás enfocando a control de grupo, [...] a lo mejor a tener algunas estrategias, a lo mejor a revisar algunos libros, a lo mejor a tener un repertorio... y con eso se piensa que eso es todo [...] ¿qué es lo que vas a enseñar? Ok, te encuentras un alumno de primaria que resulta que tiene un oído formidable y se da cuenta si tú te desafinas... (Profesor de Educación Musical no. 3).

A uno de los egresados de la UNAM, cuando realizó su examen de admisión para la Licenciatura en Educación Musical le cuestionaron por tener un nivel "innecesariamente" alto para este programa:

Creo que venía con un nivel bueno, inclusive una de las observaciones que hicieron cuando llegué a alguna de las interpretaciones, "sí — dijeron-, bueno, ¿y qué haces aquí?, o sea, ¿por qué estás en educación musical, no?,

29 El presente trabajo de investigación se realizó teniendo como base los planes de estudios de la UNAM que están en proceso de perder vigencia. Esto se debe a que el nuevo plan se comenzó a aplicar en el segundo semestre de 2009, al mismo tiempo que se sigue aplicando el viejo plan hasta su desaparición total en el año 2016. En este nuevo plan se pretende enfatizar las prácticas docentes, sin embargo, por lo novedoso de este programa, todavía no pueden sacarse conclusiones sobre la relevancia brindada a estas prácticas docentes. 
o sea, eh, pues tú deberías estar viniendo para piano — concertista- o una cosa así..." (Egresado no. 6).

Sobre la importancia de que las competencias musicales sean desarrolladas a nivel profesional de creación e interpretación musical, uno de los informantes comenta:

Lo que podría decir es que me parece insensato que una persona que se dedica a la educación musical no haya ejercido la música, eh, como intérprete de algún modo, es decir; y de manera medianamente sólida [...] bastaría con que hayan cantado en un coro una cierta cantidad de años un cierto repertorio, pero que hayan vivido esto porque, ¿cómo vas a enseñarle a alguien que se dirija para allá si no sabes de lo que estás hablando? o sea ¿a qué te refieres? ¿no? Eh, si tú ya sabes lo que es "zumbarte" tres horas de ensayo para montar una misa de Mozart o, una serie de arreglos corales de música mexicana [...] entonces ya esa es otra cosa, le dices, le puedes decir a una persona "necesitas este tipo de concentración, necesitas este tipo de atención" ¿No? "Necesitas valorar las cosas de este modo" (Profesor no. 5).

El desarrollo de competencias didácticas, a través de prácticas docentes en situaciones reales de enseñanza-aprendizaje, tampoco se encuentra en el centro del currículo de estos estudios universitarios de Educación Musical en la UNAM:

Carece un poco, realmente, la escuela, de esa cuestión práctica, porque no podemos, eh, hacer las prácticas aquí, no hay ese espacio que se nos otorgue para realizar una práctica pedagógica, pero, eh... en mi experiencia, pues, en la cuestión laboral, es donde realizo mis prácticas... (Alumno no. 2).

Ahí no te enseñan, curiosamente, a enseñarlo, porque no hay una práctica, o sea, no hay que alguien esté viendo y "a ver, esto no lo estás haciendo bien" (Egresado no. 4).

Una opción para que los estudiantes desarrollen competencias didácticas en la ENM es la posibilidad de conseguir un trabajo profesional paralelo a sus estudios de educación musical; o por iniciativa de un profesor; o simplemente con sus mismos compañeros. 
En cuanto a trabajo con grupo, pues, las [prácticas] que yo realizaba en el jardín de niños, porque al tiempo que estudiaba estaba también en el jardín de niños (Estudiante no. 5).

Ha habido generaciones en donde los maestros, porque dejábamos el grupo de solfeo en las manos de ellos, tenían dónde practicar, pero eso era a nivel personal, eso no debe de ser, eso debe ser a nivel institucional (Profesor de Educación Musical no. 7).

En ocasiones, para los alumnos de la UNAM, las prácticas docentes se reducen a las experiencias de enseñanza con los mismos compañeros de grupo: "todas las prácticas eran 'somos el grupo, ahora pasas tú y todos los demás somos alumnos'” (Egresado no. 1)

Como se puede corroborar en los planes de estudio de la ENM, no existe ninguna materia que cubra los propósitos de desarrollar competencias didácticas en situaciones reales de enseñanza-aprendizaje, como sería el caso de una asignatura de prácticas docentes.

Es necesario considerar que la importancia de las prácticas docentes radica en que:

[...] demanda que los participantes integren sus experiencias de vida, actividades educativas formales, observaciones de campo de maestros expertos, conocimiento de contenido musical, y métodos pedagógicos en el servicio de presentaciones educativas coherentes que ayudan a los estudiantes a aprender ${ }^{30}$.

Esto debe realizarse tomando en cuenta que «no hay substituto para las experiencias de campo bien diseñadas» ${ }^{31}$. De esta manera se entiende que: «Los estudiantes universitarios, al graduarse, con frecuencia describen a las prácticas docentes como la parte más importante de su educación universitaria» ${ }^{32}$.

30 Rideout, «Research in Music Student Teaching», p. 874.

31 Leglar y Collay, «Research by Teachers on Teacher Education», p. 864.

32 Rogers, «The Student-Teaching Portfolio», p. 29. 
Es por todo lo anterior que un currículo universitario para la formación de educadores musicales debe contemplar como prioridad, para el desarrollo de competencias educativas, la buena organización y supervisión de las prácticas docentes para todos los estudiantes, en situaciones reales de enseñanza y por períodos de tiempo que impliquen una importante fracción de los estudios universitarios.

Al considerar que la música y su enseñanza es una actividad humana que implica un conocimiento principalmente procesual - que debe ser aprendido en la praxis - se observa que en los programas de estudios de la ENM no se contempla la naturaleza intrínseca de la música y su educación.

\section{REFLEXIONES FINALES}

Puesto que los programas oficiales actuales de educación musical para la educación básica en México son inoperantes, es preciso que los agentes involucrados en la creación de políticas y programas se replanteen los alcances y objetivos de esta importante área educativa, buscando un sistema de pensamiento que ofrezca un fundamento sólido a la propuesta curricular.

Además de la acción anterior, el hecho de existir un solo centro de formación universitaria para educadores musicales en una ciudad de 23 millones de personas, con planes de estudios desenfocados respecto a las exigencias de la naturaleza intrínseca de la música, reclama a los educadores la necesidad de ofrecer nuevas opciones de esta formación en otras universidades de la Ciudad de México.

Se considera que el desarrollo de competencias musicales y pedagógicas en prácticas reales de creación y enseñanza musical deben ser el centro de la formación universitaria de educación musical. Esto es (como lo señalan los informantes y lo sustenta la filosofía praxial de la educación musical): el estudiante de educación musical debe desarrollarse lo más ampliamente posible como creador e intérprete musical, y buscar un equilibrio de estas competencias musicales con el 
desarrollo competencias didácticas; adquiridas en prácticas reales de creación musical y de enseñanza-aprendizaje - principalmente a través de prácticas docentes-, y considerando al conocimiento verbal o teórico como apoyo al musical y didáctico, y no como centro del currículo como ocurre en los programas actuales de la SEP y de la ENM, donde se favorece el conocimiento teórico sobre el práctico.

Por la perspectiva que esta investigación ofrece respecto al perfil que un educador musical debe poseer, el presente trabajo concluye que al educador musical se le identifique como: el músico que sabe enseñar aquello que lo hace ser músico.

Los mismos fundamentos que aquí se proponen para la formación universitaria del educador musical, también sirven como guías generales sobre el diseño curricular de esta educación en México. Esto es, el currículo de la educción básica debe estar fundamentado en la naturaleza procesual de la música y sus componentes: el creador, un medio por el cual se crea música, el producto musical y el contexto.

Este trabajo desea contribuir a dar respuesta a una cuestión que inaplazablemente demanda la educación musical en México: la profesionalización del educador musical. 


\section{REFERENCIAS BIBLIOGRÁFICAS}

ALPERSON, P. A., «What Should One Expect from a Philosophy of Music Education?», Journal of Aesthetic Education, 25, n. 3, Autum, 1991, p. 215-42.

ARISTÓTELES, La Política, Trad. Amelie Cuesta Basterreche, Gernika, México, 2001.

COLWELL R. y RICHARDSON C., The New Handbook of Research on Music Teaching and Learning, Oxford University Press, New York, 2002.

COROMINAS, E., et al., «Percepciones del profesorado ante la incorporación de las competencias genéricas en la formación universitaria», en Revista de educación, n. 341, septiembre-diciembre, Universitat de Girona, España 2006.

CRESWELL, J.W., Educational Research: Planning, Conducting, and Evaluating Quantitative and Qualitative Research, $2^{\mathrm{a}}$. ed., Upper Saddle River, Pearson Education Inc., 2005.

DELORS, J., La educación encierra un tesoro, UNESCO, Ciudad de México, 1996.

DIARIO OFICIAL DE LA FEDERACIÓN, Acuerdo número 357 por el que se establecen los requisitos y procedimientos relacionados con la autorización para impartir educación preescolar, 3VI-2005, DOF, México.

Ley General de Educación. Nueva Ley Publicada en el Diario Oficial de la Federación, 13-VII-1993. Texto vigente: Última reforma publicada en el Diario Oficial de la Federación, 19VIII-2010, México.

DÍAZ, M. (coord.), Introducción a la investigación en Educación Musical, Enclave Creativa, Madrid, 2006.

DÍAZ, M. y GIRÁLDEZ A. (coords.), Aportaciones teóricas y metodológicas a la educación musical, GRAÓ, Barcelona, 2007. 
ELLIOTT, D.J., «Rethinking Music Teacher Education», Journal of Music Teacher Education, n. 2, 1992, p. 6.

York, 1995.

Music Matters, Oxford University Press, New , (ed.), Praxial Musical Education, Oxford, New York, 2005.

HERNÁNDEZ S.R., et. al., Metodología de la investigación, McGraw-Hill Interamericana, México, 2008.

MERTENS, D. M., Research and Evaluation in Education and Psychology, Integrating Diversity with Quantitative, Qualitative, and Mixed Methods, Sage Publications, Thousand Oaks, 2005.

ORIOL DE ALARCÓN, N., «Preparación instrumental en los estudios de maestro especialista en educación musical», Investigar en la educación musical. De la teoría a la práctica, Eufonía, Didáctica de la Música, n. 38, año X, 2006.

PÉREZ PRIETO, M., «La organización de la educación musical en España desde 1970: estudio a partir de los textos legales de ámbito estatal», Aula. Revista de Enseñanza e Investigación Educativa, Universidad de Salamanca, España, 2005.

REIMER, B.A., Philosophy of Music Education, Prentice Hall, Englewood Cliffs, N.J., 1970, 1989.

SCHÖN, D.A., El profesional reflexivo; Cómo piensan los profesionales cuando actúan, Paidós, Barcelona, 1998.

SCHULMAN, L.S., The Widsdom of Practice: Essays on Teaching, Learning, and Learning to Teach, Jossey-Bass, San Francisco, 2004.

SECRETARÍA DE EDUCACIÓN PÚBLICA, Educación Artística. Quinto grado, SEP, México, 2010.

Plan de Estudios 2006. Educación Básica. Secundaria, SEP, México, 2006. 
, Plan de Estudios 2009. Educación Básica. Primaria, SEP, México, segunda edición, 2009.

Plan de Estudios 2009. Educación Básica. Primaria. Etapa de prueba, $2^{a}$. edición, SEP, México, 2009. México, 2004. , Programa de Educación Preescolar 2004, SEP,

SMALL, C., Musicking: The Meanings of Performing and Listening, Wesleyan University Press, Middletown, Connecticut, 1998.

SUZUKI, S., Nurtured by love, Warner Bros., Miami, 1983.

EMDEMUS, México, 2007. , Desarrollo de las habilidades desde la edad cero, UNIVERSIDAD NACIONAL AUTÓNOMA DE MÉXICO, Proyecto de Modificación del Plan de Estudios de la Licenciatura en Música-Educación Musical, Resumen Ejecutivo, UNAM, México, 2007.

VILLALOBOS PÉREZ-CORTÉS, E.M., Didáctica integrativa y el proceso de aprendizaje, Trillas, México, 2002.

, Evaluación del aprendizaje basado en competencias, Minos III Milenio, México, 2009. 